\title{
WWLLN Data Cluster Analysis Methods for Lightning-Caused Forest Fires Monitoring
}

\author{
Baranovskiy Nikolay ${ }^{1}$, Krechetova Svetlana ${ }^{2}$, Belikova Marina ${ }^{3}$, Perelygin Anton ${ }^{4}$ \\ ${ }^{1,3,4}$ Departement of Theoretical and Industrial Heat Systems Engineering, Tomsk Polytechnic University, \\ Russian Federation \\ ${ }^{2}$ Department of Mathematic and Computer Sciences, Gorno-Altaysk State University, Russian Federation
}

\begin{tabular}{l} 
Article Info \\
\hline Article history: \\
Received Sep 26, 2016 \\
Revised Nov 7, 2016 \\
Accepted Nov 21, 2016 \\
\hline
\end{tabular}

\section{Keyword:}

Cluster analysis

Forest fire

Lightning monitoring

Siberia

WWLLN data

\begin{abstract}
Storm activity is the main reason for forest fires to occur in remote forested territories. The current article presents the results for cluster analysis of WWLLN data on lightning discharges. It provides the description for clusterization algorithms of lightning discharges over the controlled territory. Research area is Timiryazevskiy forestry of the Tomsk region (Siberia, Russia). We analyzed the applicability of cluster analysis results for monitoring of the forest fire danger caused by storm activity. As a result of the conducted research, we established that the following characteristics of storm activity can be included in deterministic-probabilistic criterion to assess the forest fire danger. The article gives the recommendations how to create new generation information-computer and geoinformation systems for monitoring of the forest fire danger caused by storm activity in the controlled forested territory.
\end{abstract}

Copyright () 2016 Institute of Advanced Engineering and Science. All rights reserved.

\section{Corresponding Author:}

Baranovskiy Nikolay,

Departement of Theoretical and Industrial Heat Systems Engineering,

Tomsk Polytechncic University,

30 Lenin avenue, Tomsk 634050, Russian Federation.

Email:firedanger@narod.ru

\section{INTRODUCTION}

The reasons for forest fires to occur are rather various. The whole range of such reasons can be divided into two groups - natural and anthropogenic factors of forest fires occurrence [1]. The principal natural factor of ignitions in remote forests is the storm activity [2]. Forest fires cause not only economic damage, but also lead to death of people and to ecological effects [3].

The analysis of forest fire incidents for recent years (especially for which it is typical to have great values of the area covered by the fire) shows that it is ineffective to extinguish large forest fires by the modern ways [4]. We believe that the greatest effect on minimization of negative consequences of forest fires can be reached using the systems of monitoring, assessment and forecasting of forest fire danger [5-6].

Now, in the world, the following forest fire danger assessment systems become widely used: Canadian [7], American [8], European [9].

The system ISDM-Rosleskhoz is applied in the territory of the Russian Federation [10]. All the specified systems have a number of essential shortcomings [1]. It is necessary to develop the new deterministic-probabilistic approach to assess, monitor and forecast the forest fire danger caused by storm activity [11-12].

Ground storm discharges are recorded in other countries as well. In the period between 1992 and 2001, scientists conducted a cycle of observations on ground-to-cloud storm discharges in one of the regions in Spain [13]. The characteristics of $4,3 \cdot 10^{6}$ flashes were registered for the Iberian Peninsula during the first ten years of storm monitoring network operation: the yearly and daily cycle, polarity, complexity, peak 
current of the first strike. It was shown that the maximum storm activity is characteristic of the period from May to September. The maximum stroke frequency was 2,1 strokes $/\left(\mathrm{km}^{2}\right.$ year). The maximum storm activity is associated with the mountainous landscape. The share of single strokes was 53,6\% and $89 \%$ correspondingly for negative and positive ground storm discharges. The average current for the first stroke of the negative and positive discharges was $23,5 \mathrm{kA}$ and $35,3 \mathrm{kA}$ correspondingly. The peak current for discharges of both polarities is higher in the summer than in the winter.

For an effective operation of forest protection service, it is necessary to know the dynamics of storm activity in the certain region. For example, the storm activity in the Krasnoyarsk Territory varies substantially within a day. Along with that, the highest degree of storm repetition is observed between 14 and 18 o'clock [14]. The average storm duration varies from 1,2 to $2.6 \mathrm{~h}$. Within one day, the biggest number of storms is recorded between 12 and 18 o'clock, local time [14]. Several factors influence the storm-induced forest fire occurrence: 1) storm's passing, 2) presence of the cloud-to-ground discharge, 3) the amount of precipitation fallen during the storm, 4) the tree species and its physical state, 5) the presence of fuels, 6) soil conductivity. The biggest number of ground lightning discharge occurs at night or early morning [14]. Forest fuel ignition occurs at night. In the early morning, the dew formation creates unfavorable conditions for fire to spread in this period. Fires often occur only after a durable break in time after the storm [15].

In Russia, in the period from 1992 till 2000, storm-induced forest fires equaled 37 to $53 \%$ of the area on which fire had spread, with a relative number of 8.8-17.5\% [16]. Dry storms, producing mass inflammations on large spaces, often create a very intense situation [14].

The most known GIS-systems at present are as follows:

1. Information system of remote monitoring of forest fires ISDM-Rosleskhoz (Russia) [10]. The current fire danger is assessed relying on Nesterov criterion which has no physical basis under itself. The minimum territory is a zone of responsibility of a separate meteorological station. The National Research Tomsk Polytechnic University implemented in this system the probabilistic criterion to assess the forest fire danger with regard to the storm activity and anthropogenic impact.

2. Canadian Forest Fire Danger Rating System CFFDRS (Canada) and National Fire Danger Rating System NFDRS (USA) [7],[8]. The forest fire danger is assessed relying on the analysis of big arrays of statistical information on large forested territories. The system considers the reasons why forest fires occur (anthropogenic impact and storm activity).

3. European Forest Fire Information System EFFIS (Europe) [9]. The most progressive component of system repeats a subsystem of the Canadian Forest Fire Danger Rating System. It has the same characteristics and uses the Earth remote sensing data.

4. GIS of Tomsk State University (Russia) [17]. The system considers the mathematical model of drying the forest fuel layer. Ignition processes are not considered. The minimum territory is the forest mensuration stratum.

5. Virtual Fire System (Greece) [18]. It uses web services to display the information. It includes the assessment of forest fire danger relying on the analysis of meteorological data. is There is no data about the minimum territory. There is an opportunity to predict process of forest fire spreading.

6. Fire Station (Portugal) [19]. The reasons for forest fire to occur are not considered. There is a possibility to forecast the forest fire spreading.

The detailed analysis of the specified systems shows that to assess the probability of forest fires occurrence by storm activity, generally statistical data on the specified territory are used. However, data of the WWLLN [20] network on lightning discharges are available practically across the territory of the whole world, including across Western Siberia. It is necessary to analyze the possibility how to apply these data for monitoring, assessment and forecasting of forest fires. Timiryazevskiy forestry of the Tomsk region is considered as the typical territory [1].

The Tomsk Region, its northern part, in particular, is a fairly typical forested territory of a boreal forest zone. Its example may provide a quite general description of the conditions for fire occurrence. The region has vast forest resources. Forest areas cover $90.5 \%$ of its total territory. There are 17 million hectares covered with woody species, including 9.9 million hectares covered with coniferous species.

The main landscape types within the Tomsk Region are interfluvial plains and river valleys along with old runoff plains. Interfluvial plains are represented by positive and negative morphostructures. Figure 1 shows the geomorphological demarcation of the Tomsk Region.

The region's forests are located in the Ob River basin on a plain territory with an excessive moistening of the territory and are essential in nature protection. Relatively harsh weather conditions determine the rather limited species composition of forests.

Forest fire danger in the Tomsk Region is determined by the presence of a large proportion of coniferous forests, well-developed flammable ground vegetation and hot, dry summers. The climate of the Tomsk Region is boreal-type extreme continental. Territories with continental climate create conditions 
especially favorable for forest fire occurrence. In the region's forests, depending on the weather conditions, all three seasonal flammability peaks are registered: spring fire wave, constant summer and autumn fires [1]. Up to $37 \%$ of forest fires caused by storm activity occur in the territory of the Tomsk region [21].

Thus, it is necessary to attract all available information on storm activity in the studied territory, including new data sources, for example, data of WWLLN. And also new methods. Modern researches show that the cluster analysis is successfully used not only as an independent method to detect the regularities. It can be used as base both for creation of hybrid predictive models [22], and for studying of existential regularities [23-25].

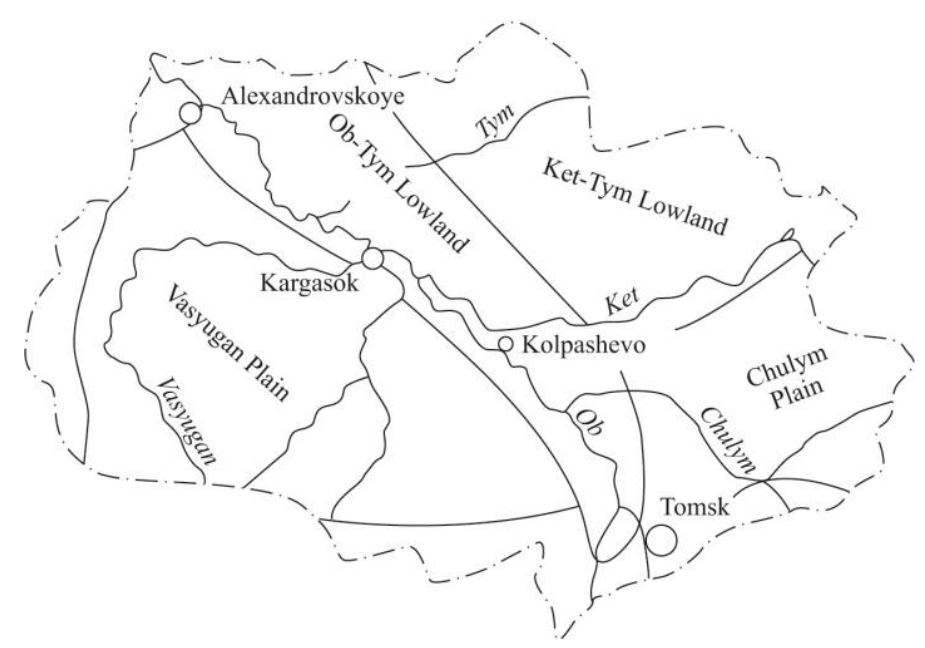

Figure 1. Geomorphological Division into Districts of the Tomsk Region [26]

Research objective is cluster analysis of WWLLN data on lightning discharges in the typical territory of Western Siberia and an assessment of possible applicability of these data and methods to monitor the forest fire danger caused by storm activity.

\section{RESEARCH METHOD}

\subsection{DBSCAN Algorithm}

Density-based clustering algorithm DBSCAN (Density-Based Spatial Clustering of Applications with Noise, as proposed by Martin Ester [27], is widely used in applied researches, including for clustering data of WWLLN for a world scale.

In the algorithm, the cluster is the coherent dense (density-connected) set of points. The algorithm has two parameters: maximum radius of the neighborhood Eps and minimum number of points in the Eps-neighborhood MinPts .

Relying on the notions «Eps-neighborhood», «density-reachable» and «density-connected», «marking» of all points of set are performed on the «core point», boundary points and waste (noise).

Given a set of objects $D$ which contains N objects, a distance function dist: $O \times O \rightarrow R$ and two parameters Eps $\in R^{+}$and MinPts $\in N^{+}$.

Eps-neighborhood of a point $q$ is a called as the set of points, the distance to which does not exceed Eps, that is, $N_{E p s}(q): p \in D \mid \operatorname{dist}(p, q) \leq E p s$.

A point $P$ is directly density-reachable from a point $q$ w.r.t. ${ }^{E p s}$, MinPts if $p$ belongs to $N_{E p s}(q)$ and $\left|N_{E p s}(q)\right| \geq \operatorname{MinPts}$.

A point $p$ is density-reachable from a point $q$ w.r.t. Eps, MinPts if there is a chain of points $p_{1}, \ldots, p_{n}, p_{1}=q, p_{n}=p$ such that $p_{i+1}$ is directly density-reachable from $p_{i}$.

A point $P$ is density-connected to a point $q_{\text {w.r.t. }}{ }^{E p s}$, MinPts if there is a point $O$ such that both $p$ and $q$ are density-reachable from $O$ w.r.t. ${ }^{\text {Eps }}$, MinPts. 

core points

Points which are inside of a cluster and have not less than MinPts -neighbours and are also called as border points.

Points having less than MinPts-neighbors, but density-reachable from any kernel are called as

Points not belonging to Eps-vicinities of any core point are outlier points (noise). pseudo-code.

Require: Eps-radius of Eps-neighborhood; MinPts - the minimum number of elements, which have to get in Eps-neighborhood of each element of a kernel.

for each point $p$ in dataset $D$

if $p$ it has not been referred to a cluster or to emissions yet then reatrieve all points density-reachable from $p$ w.r.t Eps and MinPts

if $p$ is core point, a cluster is formed

if $p$ is a border point, no points are density-reachable

from $p$, a point $p$ is outlier (noise), and DBSCAN visits

the next point in dataset $D$

End if

End for

\subsection{Clustering WWLLN for Siberia (Tomsk Region)}

The WWLLN network provides the following information on a lightning discharge: date, time, geographical coordinates, accuracy, and number of the stations which registered the discharge.

The definition of proximity of two discharges is influenced by not only geographical coordinates of categories, but also by the time of their registration (two discharges get into one cluster, if distance and a difference on registration time for discharges is less than the set thresholds). Therefore, each discharge of $p$ have three characteristics: coordinates of the discharge of $\left(x_{1}, x_{2}\right)$ and time of registration of the discharge of $\left(x_{3}\right)$. Thus, the lightning discharge of $p$ can be described by means of a set of three material variables $x(p)=\left(x_{1}, x_{2}, x_{3}\right)$. Set of $P=\left\{p^{(1)}, p^{(2)} \ldots, p^{N}\right\}$ containing $N$ of lightning discharges, can be presented as a set of $N$ points in three-dimensional Euclidean space of $E_{3}$.

Distance for each couple of objects (atmospherics) of $p^{(i)}$ and $p^{(l)}$, where $i, l=1 \ldots, N$ and $i \neq l$, we will calculate as follows:

$$
\rho_{E_{2}}\left(p^{(i)}, p^{(l)}\right)=\sqrt{\sum_{j=1}^{2}\left(x_{j}^{(i)}-x_{j}^{(l)}\right)^{2}}
$$

and a difference in time of registration of discharges of

$$
\tau\left(p^{(i)}, p^{(l)}\right)=\left|x_{3}^{(i)}-x_{3}^{(l)}\right|
$$

Here $\left(x_{1}^{(i)}, x_{2}^{(i)}\right),\left(x_{1}^{(l)}, x_{2}^{(l)}\right)$ - geographical coordinates, and $x_{3}^{(i)}, x_{3}^{(l)}$ - time of registration of categories of $p^{(i)}$ and $p^{(l)}$. Threshold values for $\rho_{E_{2}}$ and $\tau$ are Eps and Eps time respectively.

For the cluster analysis of WWLLN data we chose the region, covering the Timiryazevsky forest area of the Tomsk region (border $\square(55.93-56.86)^{\circ}$ of NL, $\square(83.94-85.07)^{\circ}$ of EL) and the summer period of 2014. We had the selection consisting of 1755 discharges.

Parameters of algorithm of clusterizing Eps, Eps $s_{\text {time }}$ and MinPts significantly influence on the number, the average duration and the average area of "cluster" storms. One should choose the algorithm parameters so that the characteristics of "cluster" storms corresponded to the characteristics of storm activity for the chosen region.

For the territory of the Tomsk region, the characteristics of storm activity are determined by data of hydrometeorological stations. A network of hydrometeorological stations is rare; therefore, more or less 
reliable data are the data on the average duration of storms on days with the storm. The quantity of storms according to hydrometeorological stations is less, than according to the WWLLN network. It is impossible to calculate the average area of storms according to hydrometeorological stations.

In order to determine the optimum parameters of Eps, Eps $s_{\text {time }}$ and MinPts, we conducted a series of

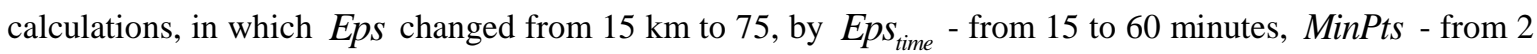

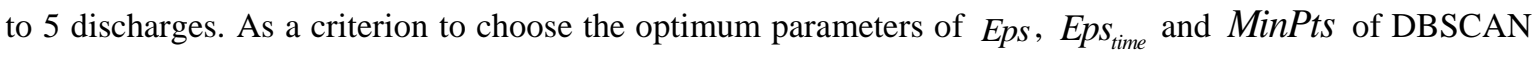
algorithm, we used the average duration of storms on days with the storm. For the Tomsk region it has the value of $1.8-2.4$ hours, the total number of «noise» points, which must be the smallest. The Figure 1 shows that the best compliance between the average duration of storms and the average duration of «cluster» storms occurs at Eps $=20 \mathrm{~km}, E p s_{\text {time }}=30 \mathrm{~min}$ and MinPts $=3$. The found parameters of DBSCAN algorithm correspond to the average extent and time of existence of a one-cell storm.

\section{RESULTS AND ANALYSIS}

The "cluster" storms, obtained as a result of the cluster analysis with the chosen optimum parameters of Eps, Eps $s_{\text {time }}$ and MinPts, were compared with data of hydrometeorological stations. We compared the days with registration of lightning discharges and days when the storm was recorded on Tomsk meteorological station (Table 1). The Tomsk meteorological station is in the northeast of the considered territory. According to WWLLNN data, 29 days with the storm were registered in the considered territory, on Tomsk meteorological station - 16 days with the storm. On meteorological stations, storms are observed by acoustical and visual method and, in most cases, strong storms are recorded. Therefore, days with small number of the lightning discharges recorded by WWLLN were not marked out as days with the storm.

By a number of the lightning discharges using WWLLN, it is possible to mark out the days with the most intensive storms. The greatest number of lightning discharges is noted on July 22. Therefore, we analyzed in details the temporary and spatial distribution of clusters of lightning discharges constructed for input parameters of Eps $=20 \mathrm{~km}, E_{\text {time }}=30 \mathrm{~min}$ and $\mathrm{MinPts}=3$ namely on this day.

Table 2 gives the time for the first and last lightning discharge which entered a cluster, and relying on these data, we calculated the duration of cluster storm activity. Time of beginning and end of "cluster" storms coincides with real storms.

Figure 2 represents the spatial distribution of clusters, obtained on water conditions 20, 3, 20, on July 22. Thus, the cluster 54, which contains the greatest number of discharges, is taken out separately. Serial numbers of clusters correspond by time (Table 2) of sequence of occurrence and action of clusters that allows us to see a trajectory of their movement. So, the first cluster at number 48 arises practically in the center of the considered territory. Then, the lightning activity is displaced on the northwest of the 49th and the 50th clusters. The next cluster 51 arises to the east of the previous one. Practically, at the same time, there is an action of a cluster 51 in the northeast, of a cluster 52 in the southwest of the territory and of a cluster 53. Then, approximately in a half an hour to the southwest of the territory, there is a powerful rash of lightning discharges within more than 3 hours, which belongs to a cluster 54 . Thus, the scope of a cluster 54 also extends on the territory, where the storm clusters operated earlier. Most likely, the cluster 55 is also a part of the cluster 54, which is already ceasing its activity.

Lightning flashes of the cluster 54, were recorded on Tomsk meteorological station. According to data of Tomsk meteorological station, on this day, in separate hours, the storm without precipitation was observed (reliable prognosis rp5.ru).

By the time of its action, the marked out clusters correspond to descriptions of parameters of storm cells. Thus, clusters 48, 49,50, which time of action is less than an hour and the distance between discharges does not exceed $20 \mathrm{~km}$, can be referred to one-cell storms. In case if duration of action of a cluster is several hours, such as, the cluster 54, or there are some separate clusters, which emergence time practically coincides, they can be considered as an analog of the multicell storm. 

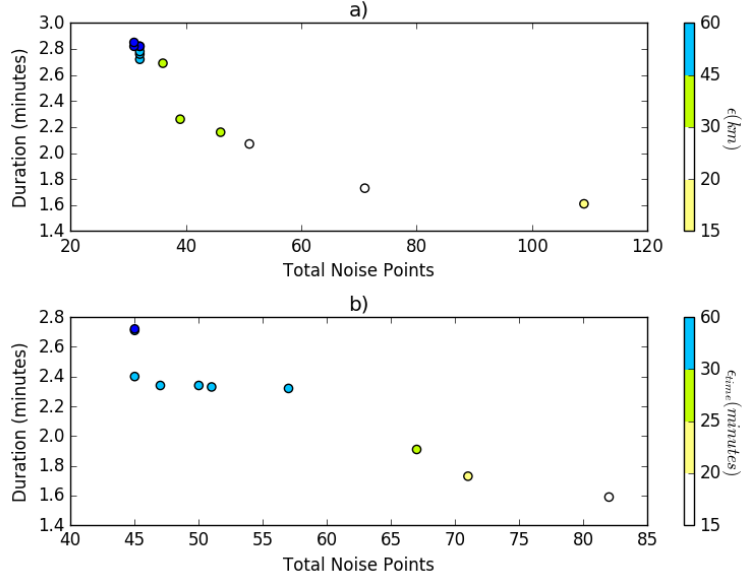

a) - Eps varies from 15 to $75 \mathrm{~km}$; b) - Eps $s_{\text {time }}$ varies from 15 to $60 \mathrm{~min}$;

Figure 2. Variation in Average Cluster Storm Duration and Total Noise Points Through Varying One Clustering Parameter with the others Held Constant

(constant set: $E p s=20 \mathrm{~km}, \mathrm{Eps}_{\text {time }}=30 \mathrm{~min}$, and MinPts $=3$ );

Table 1. Dates of Registration of Lightning Discharges and Registration of Storms for Tomsk Meteorological Station (According to the Data of Reliable Prognosis rp5.ru)

\begin{tabular}{|c|c|c|c|c|}
\hline Date & $\begin{array}{l}\text { the first lightning } \\
\text { discharge (UTS) }\end{array}$ & $\begin{array}{c}\text { the recent lightning } \\
\text { discharge (UTS) }\end{array}$ & $\begin{array}{c}\text { the number of } \\
\text { lightning strikes }\end{array}$ & $\begin{array}{c}\text { weather station } \\
\text { Tomsk }\end{array}$ \\
\hline 2014-04-19 & $11: 48$ & $11: 48$ & 1 & Not \\
\hline 2014-05-03 & $14: 24$ & $17: 07$ & 72 & Yes \\
\hline 2014-05-04 & $18: 56$ & $22: 28$ & 36 & Yes \\
\hline $2014-05-13$ & $9: 54$ & $11: 28$ & 4 & Not \\
\hline $2014-05-21$ & $4: 33$ & $9: 09$ & 11 & Yes \\
\hline $2014-05-24$ & $0: 38$ & $9: 36$ & 35 & Yes \\
\hline 2014-06-10 & $9: 39$ & $11: 41$ & 6 & Not \\
\hline 2014-06-19 & $8: 28$ & $10: 39$ & 17 & Yes \\
\hline $2014-06-26$ & $7: 30$ & $10: 46$ & 145 & Yes \\
\hline 2014-07-02 & $14: 08$ & $14: 08$ & 1 & Not \\
\hline 2014-07-07 & $7: 45$ & $7: 45$ & 1 & Not \\
\hline 2014-07-09 & $0: 13$ & $1: 53$ & 6 & Not \\
\hline 2014-07-10 & $23: 58$ & $23: 59$ & 4 & Not \\
\hline 2014-07-11 & 0:01 & $6: 33$ & 17 & Not \\
\hline 2014-07-13 & $12: 07$ & $21: 19$ & 273 & Yes \\
\hline 2014-07-19 & $19: 04$ & $19: 15$ & 3 & Not \\
\hline $2014-07-22$ & $13: 27$ & $22: 29$ & 341 & Yes \\
\hline $2014-07-23$ & $11: 54$ & $23: 27$ & 178 & Yes \\
\hline $2014-07-26$ & $5: 53$ & $15: 40$ & 158 & Yes \\
\hline $2014-07-27$ & 10:11 & $12: 13$ & 9 & Not \\
\hline 2014-07-29 & $1: 42$ & $1: 42$ & 1 & Not \\
\hline $2014-08-06$ & $7: 47$ & $9: 30$ & 24 & Yes \\
\hline 2014-08-11 & $17: 09$ & $21: 13$ & 76 & Yes \\
\hline 2014-08-12 & $10: 18$ & $10: 18$ & 1 & Not \\
\hline $2014-08-13$ & $2: 43$ & $13: 58$ & 82 & Yes \\
\hline 2014-08-15 & $16: 22$ & $16: 57$ & 2 & Yes \\
\hline 2014-08-24 & $21: 35$ & $23: 36$ & 36 & Yes \\
\hline $2014-08-25$ & $0: 03$ & $20: 28$ & 209 & Yes \\
\hline $2014-09-23$ & $10: 24$ & $10: 50$ & 6 & Not \\
\hline
\end{tabular}

In general, the conducted cluster analysis allows us to mark out more detailed behavior of storm activity in the considered territory. We can observe a good coherence of time to register the days with WWLLN storm and network of meteorological stations in case of a large number of lightning discharges (more than 20). Let's note that most often, the storm fires occur on suburbs of storm fronts, where there is the smaller number of rainfalls, and there is a high probability of positive lightning discharges to emerge. 
Table 2. Parameters of Clusters at Initial Conditions 20, 3, 30

\begin{tabular}{ccccc}
\hline Cluster Number & Start Time & End Time & Duration & Number of Discharges \\
\hline 48 & $13: 27$ & $14: 08$ & $0: 41$ & 18 \\
49 & $14: 34$ & $14: 47$ & $0: 13$ & 10 \\
50 & $15: 27$ & $15: 39$ & $0: 12$ & 3 \\
51 & $16: 55$ & $17: 42$ & $0: 47$ & 15 \\
52 & $17: 08$ & $17: 50$ & $0: 42$ & 15 \\
53 & $17: 22$ & $17: 35$ & $0: 13$ & 3 \\
54 & $18: 54$ & $22: 29$ & $3: 35$ & 3 \\
55 & $21: 28$ & $21: 41$ & $0: 13$ & 7 \\
Noise & & & & \\
\hline
\end{tabular}

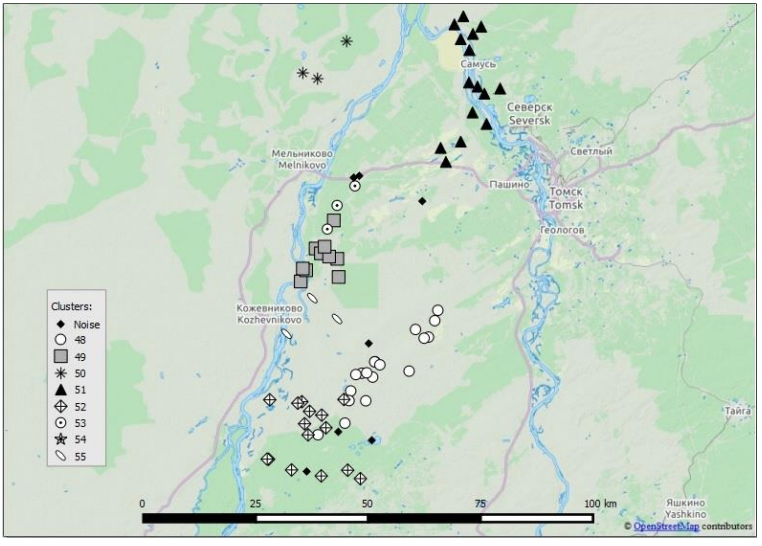

(a)

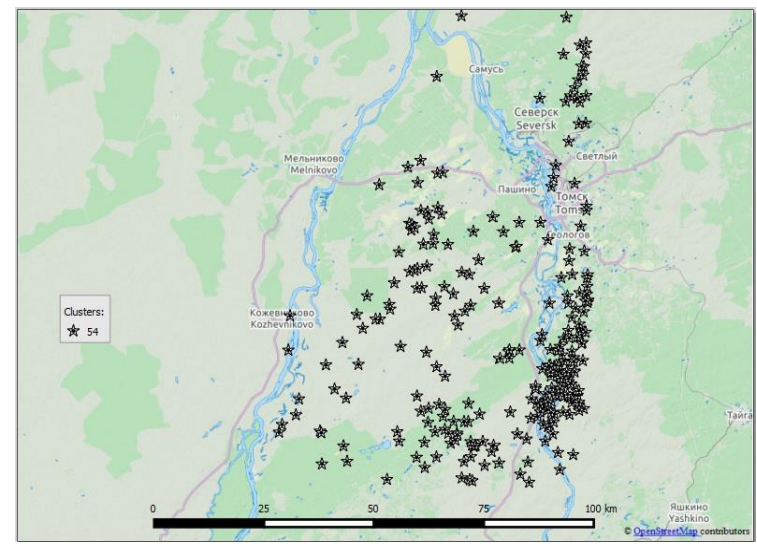

(b)

Figure 3. The clusters of lightning discharges obtained for input parameters Eps $=20 \mathrm{~km}, E_{\text {time }}=30 \mathrm{~min}$, and MinPts $=3: \mathrm{a}-$ representation of clusters without cluster under number 54; b - representation of cluster 54

The cluster analysis of the lightning discharges WWLLN allows us to determine a scope of storm cells and, respectively, in future, it is possible to define a place of probable fire emergence under otherwise equal conditions as shown in Figure 3.

The analysis of results shows that after data processing of the WWLLN network on lightning discharges, it is possible to form a layer in GIS with information on clusters of storm activity in the controlled territory. This information can be used as input information in order to assess the level of forest fire danger from storms.

\section{CONCLUSION}

Resulting from our research, we conducted the cluster analysis of lightning discharges according to WWLLN data for the typical territory of Western Siberia (Russia). The research area is the territory of the Timiryazevskiy forestry of the Tomsk region. We presented the descriptions of methods for data clustering. We chose the optimum parameters of the cluster analysis. We gave typical results of work of algorithm by the analysis of lightning discharges for a forest fire season of 2014. The use of WWLLN data allows us to obtain the input information to assess the forest fire danger in the conditions of storm activity in the controlled territory.

\section{ACKNOWLEDGEMENTS}

Work is implemented at financial support of the Russian Foundation for Basic researches and Administration of Tomsk Region. The grant 16-41-700831. The authors wish to thank the World Wide Lightning Location Network (http://wwlln.net), collaboration among over 50 universities and institutions, for providing the lightning location data used in this paper. 


\section{REFERENCES}

[1] Kuznetsov G. V. and Baranovskiy N. V., "Forecast of forest fires occurrence and their ecological consequences," Novosibirsk: Publishing house of the Siberian Branch of the Russian Academy of Science, 2009.

[2] Podur J., et al., "Spatial patterns lightning-caused forest fires in Ontario 1976 - 1998," Ecological Modelling, vol. 164, pp. $1-20,2003$.

[3] Collins R. D., et al., "Forest fire management to avoid unintended consequences: A case study of Portugal using system dynamics," Journal of Environmental Management, vol. 130, pp. 1 - 9, 2013.

[4] Gupta M., et al., "Experimental evaluation of fire suppression characteristics of twin fluid water mist system," Fire Safety Journal, vol. 54, pp. 130-142, 2012.

[5] Taylor S. W. and Alexander M. E., "Science, technology and human factors in fire danger rating: Canadian experience," International Journal of Wildland Fire, vol. 15, pp. 121 - 135, 2006.

[6] Baranovskiy N. V., "Project of Eurasian Segment of the New System of Forest Fire Risk Prediction Based on Information and Computer Technologies," Journal of Automation and Information Sciences, vol. 47, pp. 40-56, 2015.

[7] Bibliography on the Canadian Forest Fire Danger Rating System. 1969-1985 (with 1986 and 1987 supplements) 1988. Alexander, M.E., compiler. Canadian Forestry Service, Northern Forestry Centre, Edmonton, AB.

[8] Deeming J. E., et al., "The National Fire-Danger Rating System," Ogden, Utah: USDA Forest Service, General Technical report. INT-39, 1978.

[9] Camia A., et al., "Fire danger rating in the European Forest Fire Information System (EFFIS): Current developments," Forest Ecology and Management, vol. 234, 2006.

[10] Loupian E. A., et al., "Satellite data processing management in Forest Fires Remote Monitoring Information System (ISDM-Rosleskhoz) of the Federal Agency for Forestry (Review)," Sovremennye Problemy Distantsionnogo Zondirovaniya Zemli iz Kosmosa, vol. 12, pp. 222 - 250, 2015.

[11] Baranovskiy N. V. and Zharikova M. V., "A Web Oriented Geoinformation System Application for Forest Fire Danger Prediction in Typical Forests of the Ukraine," Lecture Notes in Geoinformation and Cartography, Thematic Cartography for the Society, pp. 13 - 22, 2014.

[12] Kuznetsov G. V., et al., "Mathematical simulation of heat transfer at deciduous tree ignition by cloud-to-ground lightning discharge," EPJ Web of Conferences, vol. 82, pp. 1-6, 2015.

[13] Soriano L. R., et al., "Ten-year study of cloud-to-ground lightning activity in the Iberian Peninsula," J. Atmosp. and Solar-Terrestr. Phys, vol. 67, pp. 1632 - 1639, 2005.

[14] Ivanov V. A., "Storm activity and forest fires," Forest fires and fight against them /Moscow: VNIILM, 1987.

[15] Larjavaara M., et al., "Spatial distribution of lightning-ignited fires in Finland," Forest Ecology and Management, vol. 208, pp. $177-188,2005$.

[16] Azmetov R. R., et al., "Prospects of creation of the Russian system of electromagnetic monitoring of thunderstorms for needs of forest conservation from the fires, power, aircraft, meteorology and forecasting of natural disasters," in Proceedings of International Conference, Conjugated problems of mechanics and ecology, Tomsk, 2000 .

[17] Grishin A. M. and Filkov A. I., "Forecast of occurrence and spreading of forest fires," Kemerovo: Practice. 2005.

[18] Kalabokidis K., et al., "Virtual Fire: A web based GIS platform for forest fire control," Ecological Informatics, vol. 16, pp. $62-69,2013$

[19] R. Aseretto D., et al., "A Data-driven Model for Large Wildfire Behaviour Prediction in Europe," Procedia Computer Science, vol. 18, pp. 1861 - 1870, 2013.

[20] Rodger C. J., et al., "Detection efficiency of the VLF World-Wide Lightning Location Network (WWLLN): initial case study," Annales Geophysicae, vol. 24, pp. 3197 - 3214, 2006.

[21] Yanko I. V., "Pyrological assessment of the territory of the Tomsk region. Diss," Tomsk: Tomsk state pedagogical university, 2005.

[22] Dong L., et al., "Wind power day-ahead prediction with cluster analysis of NWP," Renewable and Sustainable Energy Reviews, vol. 60, pp. 1206 - 1212, 2016.

[23] Parente J., et al., "Space-time clustering analysis of wildfires: The influence of dataset characteristics, fire prevention policy decisions, weather and climate," Science of the Total Environment, vol. 559, pp. 151 - 165, 2016.

[24] Pereira M. G., et al., "Space-time clustering analysis performance of an aggregated dataset: The case of wildfires in Portugal," Environmental Modelling \& Software, vol. 72, pp. 239 - 249, 2015.

[25] Strauss C., et al., "Spatio-temporal clustering and density estimation of lightning data for the tracking of convective events," Atmospheric Research, vol. 134, pp. 87 - 99, 2013.

[26] Evseeva I. S. and Zemtsov A. A., "Bulge forming in forest wetland zone of the West Siberian Plain," Tomsk, Publishing house of Tomsk University, 1990.

[27] Ester M., et al., "A density-based algorithm for discovering clusters in large spatial databases with noise," in Proceedings of the Second International Conference on Knowledge Discovery and Data Mining (KDD-96)/Eds. Simoudis E., Han J., Usama F.M. AAAI Press, 1996. 


\section{BIOGRAPHIES OF AUTHORS}
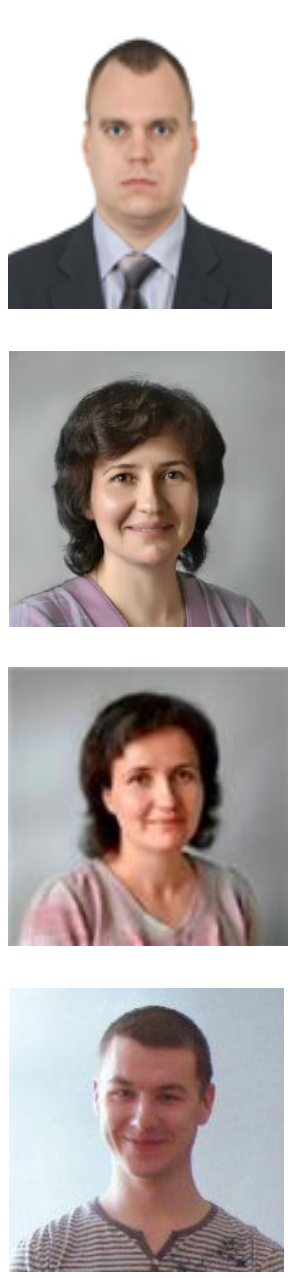

Nikolay V. Baranovskiy obtained Specialist Degree in Mechanics from Tomsk State University in 2000. He obtained PhD Degree in Physics and Mathematics from Tomsk State University in 2007. He has 16 years experience in research activity and 9 years in total in academic activity. $\mathrm{He}$ works at Associate Professor position in Tomsk Polytechnic University (Department of Theoretical and Industrial Heat Systems Engineering, Institute of Power Engineering) at present time. Field of research: fire safety and ecology, computer science. He has more 100 publication in peer-reviewed journals in English and In Russian.

Svetlana Yu. Krechetova studied at Gorno-Altaisk State University from 1996 to 2001 and received Specialist Degree in Mathematics. She obtained PhD Degree in Mathematics, Numerical Methods and Programming in 2007 from Gorno-Altaisk State University. She has 15 years in total experience in academic and research activities. Current position in Gorno-Altaisk State University is Head of Department of Mathematics and Computer Science. She is interested in physics of thunderstorms, methods of statistical and cluster data analysis.

Marina Yu. Belikova studied at Gorno-Altaisk State University from 1996 to 2001 and received Specialist Degree in Mathematics. She is currently pursuing her PhD in Mathematics. She has 15 years in total experience in academic and research activities. She works at the position of senior lecturer of the Department of Mathematics and Computer Science in Gorno-Altaisk State University. She is interested in physics of thunderstorms, data mining, cluster analysis, geoinformation systems, application programming and remote sensing.

Anton A. Perelygin studied in Gorno-Altaisk State University and obtained BSc Degree in Mathematics. He is currently doing his MSc Degree thesis in Mathematical Modelling. He has 3 years experience in research activity. He is interested in cluster analysis, mathematical modelling, programming, geoinformation systems and web-services. 